\title{
Heavy metals Fractionation in Bagmati River Sediments, Nepal
}

\author{
Sadhana Pradhanang Kayastha \\ Central Department of Environmental Science, Kirtipur \\ Tribhuvan University, Nepal
}

\begin{abstract}
The aim of this work was speciation of heavy metals on the level of the geochemical background; in bottom sediments of the Bagmati River in Kathmandu valley. The distribution and accumulation of heavy metals in the sediments of the Bagmati River were investigated. Sediment samples from six locations were collected and characterized for metals content (cadmium, lead, copper and zinc). The determination of extractable heavy metals such as, $\mathrm{Cd}, \mathrm{Pb}, \mathrm{Cu}$ and $\mathrm{Zn}$, in the sediment samples was carried out by atomic absorption spectrometry. The study has been conducted using five steps squential extraction procedure described by tessier. Apart from total concentration, the distribution of the above metals into five fractions: exchangeable, bound to carbonates, bound to Fe-Mn oxides, bound to organic matter, and residual, was studied by means of an analytical procedure involving sequential chemical extraction. The result obtained showed total metal concentration to be in the range of Cd 0.89-2.29 mg/kg; Pb 57.58-221 mg/kg; Cu 52.2 $-198.17 \mathrm{mg} / \mathrm{kg}$ and $78.23-362.90 \mathrm{mg} / \mathrm{kg}$ in all the areas studied. The fractionated toxic metals like $\mathrm{Cd}$, and $\mathrm{Pb}$ were observed to be in the range of 15-36\%, and 11-29\%, respectively, in mobile or bio-available fractions of sediments. This potentially mobile fraction could pose a serious threat, with respect to contamination of waterways and aquatic environment.
\end{abstract}

Keywords: heavy metals, sediments, Bagmati River, distribution, mobile.

\section{INTRODUCTION}

River sediments, derived as a result of weathering, are a major carrier of heavy metals in the aquatic environment, the physicochemical processes involved in their association being precipitation, adsorption and chelation (Hoda and Khaled, 2009). Besides the natural processes, metals may enter into the aquatic system due to anthropogenic factors such as mining operations, disposal of industrial wastes and applications of pesticides for pest. The concentration in sediments depends not only on anthropogenic and lithogenic sources but also upon the grain size, organic matter contents, mineralogical composition and depositional environment of the sediments (Trefry and Parsley 1976). The sediments at the bottom of the water column play a major role in the pollution of the river systems (Forstner, 1985). Pollution of heavy metals is a worldwide problem because the metals are in destructive and most of them have toxic effects on living organisms when metals exceed a certain

Email: Sadhana.pradhanang@gmail.com 
concentration (MacFarlane and Burchette 2000, Pekey, 2006). The pollution of sediments is closely linked to contamination of water by domestic sewage, industrial effluents, urban diffuse load and agriculture (Hortellani etal. 2008). Sediments have been widely used as environmental indicators, because they have great capacity to incorporate and accumulate contaminants (Filho et al. 2013). In a river ecosystem, sediment is a primary concern as related to several important issues including water quality, aquatic habitat and reservoir water-storage capacity (Juracek and Ziegler, 2009). Sediment is an important source of heavy metal pollutants as they have a long residence time (Forstner and Wittmann, 1983). Sediment serves as a sink where contaminants can be stored and also act as a source of the pollutants to the overlying water and to the inhabitants of the ecosystem (aquatic organism). Therefore, it serves as the carrier and reservoir of the heavy metals and reflects the quality of the system (Chapman and Wang, 1999). Metals that do not remain soluble in water, gets adsorbed and accumulated on bottom sediments acting as a sink (Hakanson 1980; Hongyi et al. 2009). Heavy metals are of high ecological significance since they are not removed from water as a result of self purification but accumulate in reservoirs and enter the food chain (Loska and Wiechula, 2003). The analysis of sediments carried by rivers is of prime importance as they provide insights into the physical denudation rates in the basin (Viers et al., 2009). Heavy metals are not permanently fixed on sediments and can be released back to the water column by changes in environmental conditions, such as $\mathrm{pH}$, redox potential, and chelation in the aquatic environment (Forstner, 1987; Sutherland et al., 2007). The mobility and bio-availability of heavy metal in the environment depends on their chemical forms or type of the binding of the element; this approach is very useful for site assessment and risk analysis (Howard and Shu, 1996). Thus, the chemical form of the metals in the sediment is of great significance in determining their remobilization potential (Lopez-Gonzales et al., 2006).

Bioavailability and mobilization of heavy metals in aquatic environment does not describe by total metal concentration (Singh, 2003; Zakir et al; 2008). The determination of the total concentration of the metals gives no information on their various forms (Tokalioglu, et al. 1999; Marengo et al. 2006). Therefore, sequential extraction techniques have been developed and applied to the aquatic sediment samples. The use of sequential extractions, although more time consuming, furnishes detailed information about the origin, mode of occurrence, biological and physicochemical availability, mobilization, and transport of trace metals. Speciation is not only very useful for determining the degree of association of the metals in the sediments and to what extent they may be remobilized into the environment (Forstner et al., 1990), but also for distinguishing those metals with a lithogenic origin from those with an anthropogenic origin. Metals with an anthropogenic origin are mainly obtained in the first extractions, while in the last stage of the process the residual fraction is obtained, corresponding to metals with lithogenic origins (Rubio et al. 1991; Izquierdo et al. 1997).

The Bagmati River is a major river in Nepal which originates in the central northern mountains and runs through urban areas of Kathmandu valley. The Bagmati river water has huge religious, cultural, economic and aesthetic values in this region. So, the river water has direct connection with health, environment 
and ecology and development. Bagmati River inside the Kathmandu Valley has been heavily polluted due to increasing rapid population growth; unplanned expansion of Kathmandu city and haphazard waste disposal into the river. The river is also used for discharging of untreated sewage and industrial effluents into them and the place for dumping of solid wastes and direct sewerage discharge into the river have been the major problem in the management of Bagmati River. So far many organizations are working to prevent pollution of Bagmati River but, conditions remains as it is the same or even worse. The main objective of this study was to assess distribution and accumulation of heavy metals in the sediments of the Bagmati River in Kathmandu valley. Sediment samples from six locations were collected and characterized for metals content $(\mathrm{Cd}, \mathrm{Pb}, \mathrm{Cu}$ and $\mathrm{Zn})$.

\section{MATERIALS AND METHODS}

\subsection{Sediment sampling}

Samples of sediment were collected in March 2011. A total 6 sampling sites for river bed sediment samples were collected in the Bagmati River, Nepal shown in figure 1. Bed sediment samples were collected in polyethylene bag using a stainless steel scooper where flow was low. Three random samples were taken

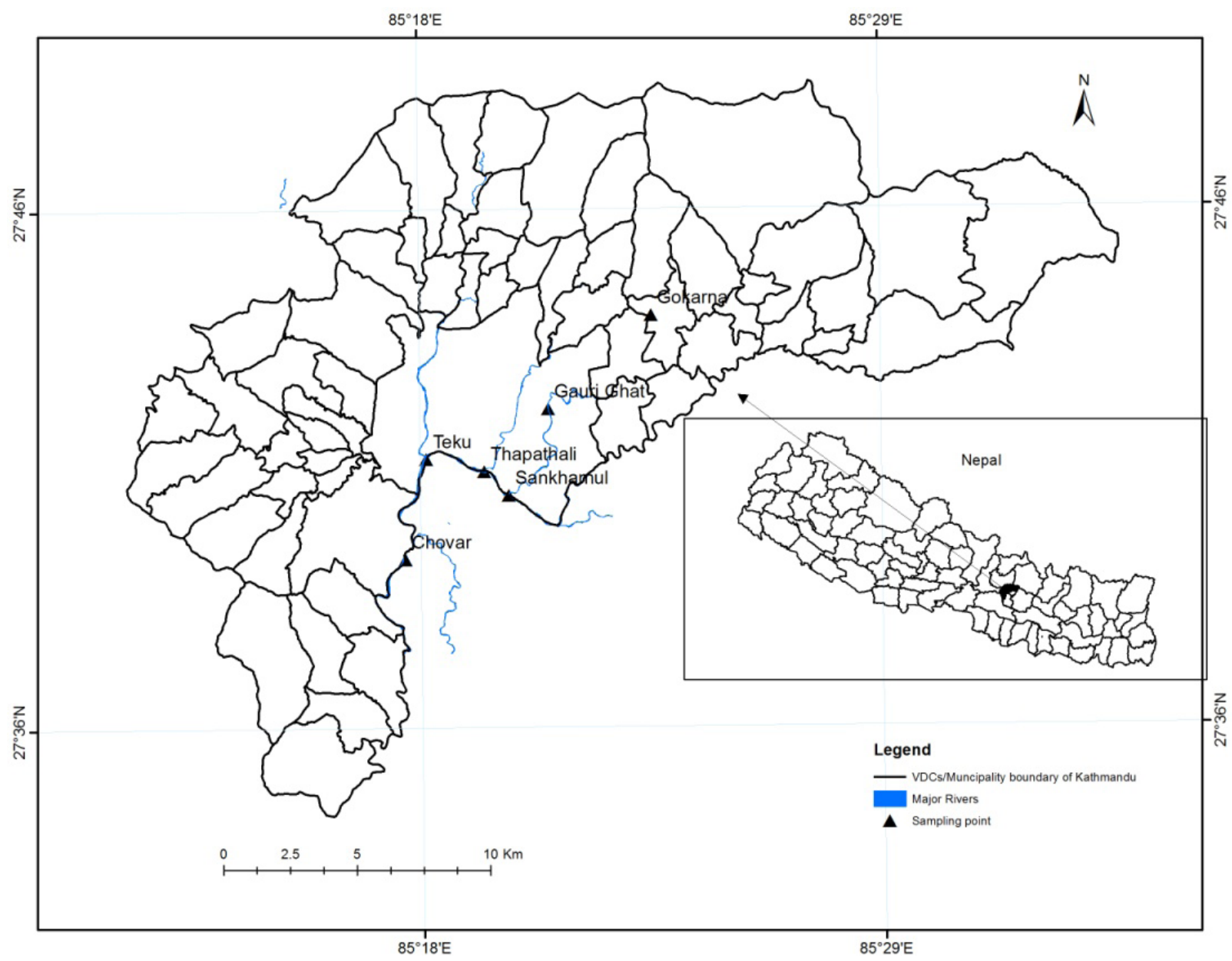

Figure 1: Sampling sites of Bagmati River, Nepal. 
from each site, which were homogenized and composite samples were stored in plastic bag with zip lock. The sediment samples were immediately sealed and stored at $4^{\circ} \mathrm{C}$ until reaching our laboratory. Sample name and sample sites were given in Table 1.

\section{Table 1: Sediment samples from}

Bagmati River

\begin{tabular}{|l|l|c|}
\hline Sample name & Site name & $\begin{array}{c}\text { Distance } \\
\text { (Km) }\end{array}$ \\
\hline B1 & Gokarna & 0 \\
B2 & Gaurighat & 8 \\
B3 & Sankhamul & 12 \\
B4 & Thapathali & 14 \\
B5 & Teku & 16 \\
B6 & Chovar & 19 \\
\hline
\end{tabular}

\subsection{Analytical methods}

The collected sediment samples were air-dried at $50^{\circ} \mathrm{C}$ for $12 \mathrm{hrs}$ at the laboratory and sieved through a $2 \mathrm{~mm}$ - sieve to remove large debris, stones and pebbles. Sediments were then ground in a mechanical agate grinder until fine particles $(<63 \mu \mathrm{m})$ were obtained.

\subsection{Metal extraction and analysis}

In the extraction procedure by Tessier et al. (1979), the metals investigation was wide ranging, but four heavy metals $(\mathrm{Cu}, \mathrm{Zn}, \mathrm{Cd}$ and $\mathrm{Pb}$ ) were analyzed in the sequential extraction (five steps). The extraction procedure was applied to all the samples by using sequential extraction methods. After each successive extraction the supernatant was separated by centrifuging at 7000rpm for 30 minutes. The supernatant obtained in each of the extractions were collected. The residue was washed with $10 \mathrm{ml}$ milli-Q water followed by centrifugation for 1 hour before the next extraction. The extraction consisted of five main steps. The analysis procedure used in detail can be given as follows:

2.3.1 Exchangeable: One gram sediment sample was extracted at room temperature for one hour with $8 \mathrm{ml}$ of $1 \mathrm{M} \mathrm{MgCl}_{2}(\mathrm{pH} 7.0)$ with continuous agitations.

2.3.2 Carbonate Bond (Acid extractable): Residue from step (1) was leached at room temperature with $8 \mathrm{ml}$ of $1 \mathrm{M}$ of sodium acetate (pH 5 adjusted with HOAc) with continuous agitation for five hours.

2.3.3 Bound to Fe-Mn Oxides (Reducible fraction): The residue obtained from step 2 through continuous agitation at $96^{\circ} \mathrm{C}$ with $20 \mathrm{ml}$ of $0.04 \mathrm{M} \mathrm{NH} \mathrm{NH}_{2} \mathrm{OH} . \mathrm{HCl}$ (Hydroxylamine hydrochloride) in $25 \% \mathrm{v} / \mathrm{v}$ acetic acid for 6 hours.

\subsubsection{Bound to Organic Matter (Oxidizable} fraction): The residue obtained from step (3); $3 \mathrm{ml}$ of $0.02 \mathrm{M} \mathrm{HNO}_{3}$ and $5 \mathrm{ml}$ of $30 \% \mathrm{H}_{2} \mathrm{O}_{2}$ was added and $\mathrm{pH}$ adjusted to $\mathrm{pH} 2$ with $\mathrm{HNO}_{3}$. The solution was agitated at $96^{\circ} \mathrm{C}$ for 2 hours and $3 \mathrm{ml}$ of $30 \% \mathrm{H}_{2} \mathrm{O}_{2}$ ( $\mathrm{pH} 2$ with $\mathrm{HNO}_{3}$ ) was added and sample was again agitated for 3 hours. After cooling, $5 \mathrm{ml}$ of $3.2 \mathrm{M}$ ammonium acetate in $20 \%$ (v/v) $\mathrm{HNO}_{3}$ was added. The sample was diluted to $20 \mathrm{ml}$ and agitated continuously for 30 minutes. The filtrate obtained in each step of the extraction was analyzed for heavy metals.

2.3.5 Residual: Residual obtained from step 4 was digested with $\mathrm{HF} / \mathrm{HNO} 3 / \mathrm{HClO}_{4}$ mixture. $100 \mathrm{mg}$ of residue was taken in a Teflon beaker and $20 \mathrm{ml}$ of acid mixture of $\mathrm{HF}, \mathrm{HNO}_{3}$ and $\mathrm{HClO}_{4}$ (in the ratio 7:3:1) was added. The Teflon 
beaker was placed in bomb digestion unit and heated $100^{\circ} \mathrm{C}$ for 2 hours. After cooling, volume was made up to $250 \mathrm{ml}$ by adding milli-Q water.

The total metal concentrations: Fresh one gm of sample was digested with $\mathrm{HF}, \mathrm{HNO}_{3}$ and $\mathrm{HClO}_{4}$ in the ratio of $7: 3: 1$.

\subsection{Metal ion analysis}

Metal ion concentrations in different extracts were determined by Shimadzu Atomic Absorption spectrophotometer (model AA6000) using air-acetylene flame. The analytical results obtained were validated with spiked samples. Operational conditions were adjusted in accordance with the manufacturer's guidelines to yield optimal determination. The percentage recovery of metals obtained by the summation of sequential fractions in relation to the total metal content extracted with aqua regia
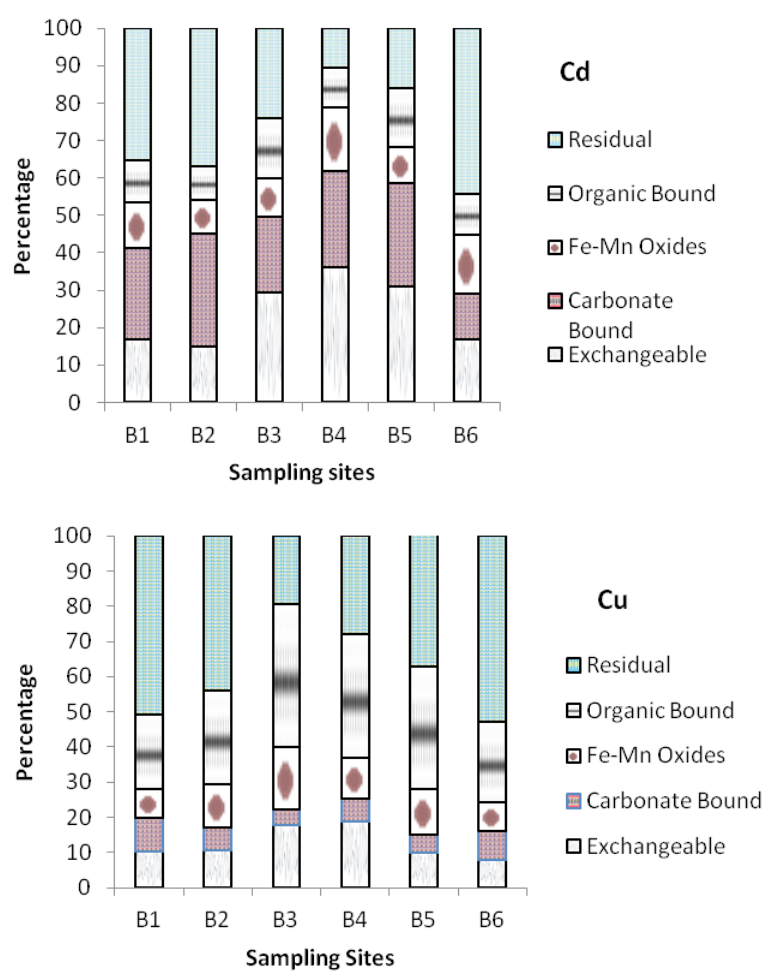

was computed. Three replicates were analyzed for each samples for metals and instruments were recalibrated every 10 samples throughout the study. Instruments were calibrated to ensure that instrument measurements do not drift.

\section{RESULTS AND DISCUSSION}

Metal concentration in the Bagmati River has been assessed for $\mathrm{Cd}, \mathrm{Pb}, \mathrm{Cu}$ and $\mathrm{Zn}$. The fractionation of trace metals in sediments are based on sequential extraction procedures. In the present study, sequential extraction procedure as proposed by Tessier et al. (1979) has been used to obtain the following five fractions:

(1) exchangeable; (2) bound to carbonate; (3) bound to Fe-Mn oxide (reducible phases);

(4) bound to organic matter and sulfides; and (5) residual. The concentrations in percent (\%) of the heavy metals determined at each

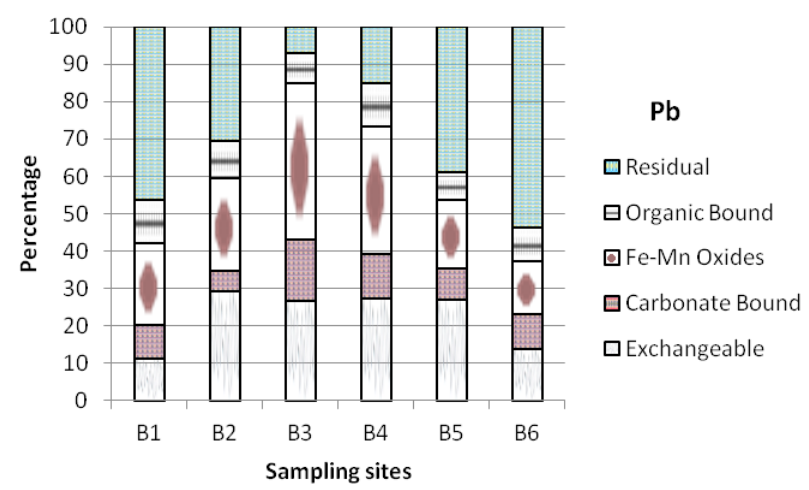

Figure 2 : Metal fraction in sediments of the Bagmati River (Exchangeable, carbonate, Fe-Mn oxide, organic and residual) 
extraction step in the sediment samples are given in Fig. 2.

The total concentration of $\mathrm{Cd}$ was varied from $0.89 \mathrm{mg} / \mathrm{kg}$ to $2.29 \mathrm{mg} / \mathrm{kg}$. The highest concentration $(2.29 \mathrm{mg} / \mathrm{kg})$ was found at site B5 (Teku). The fractionation for cadmium indicates that it is mostly bound to exchangeable, carbonate fraction (Figure 2). About 36.0\%, $31 \%$ and $29 \%$ of the total $\mathrm{Cd}$ is associated with exchangeable fraction at site 4 (Thapathali), site 5 (Teku) and site 3 (Sankhamul), respectively. This fraction has special importance due to the high mobility of heavy metals from this fraction to the aqueous phase (Jaradat et al. 2006).Significant amounts of $\mathrm{Cd}$ were found in carbonate fraction which can create very high risk to aquatic environment. The highest amount found at the sites B3, B4 and B5 in figure 2 and the rest of $\mathrm{Cd}$ was found as $\mathrm{Fe}-\mathrm{Mn}$ oxide fraction and reducible fraction and residual fractions. These results are in agreement with many previous observations ( $\mathrm{Li}$ et al. 2001; $\mathrm{Li}$ and Thornton, 2001). The most important reason of $\mathrm{Cd}$ pollution at the sites $(\mathrm{B} 1, \mathrm{~B} 2$ and B3) was mixing of untreated domestic and industrial wastewater, dumping of garbage directly, and heavy density of the traffic which have hazardous environmental impact. Once $\mathrm{Cd}$ has been incorporated into sediment, it does not re-dissolve in neutral or alkaline conditions, largely because in the anoxic conditions in the sediment cadmium sulphide is formed, which is insoluble (Dojlido and Best 1993).

The total concentration of lead was found to be 57.58 to $221 \mathrm{mg} / \mathrm{kg}$. The highest concentration was found at site (B4) Thapathali. Lead was mostly concentrated to residual fraction (inert forms), although it was present in other fractions (Fig.2). The high residual fraction may be due to the precipitation of $\mathrm{Pb}$ as stable compounds.
A significant amount of $\mathrm{Pb}$ was found to be associated with exchangeable, carbonate and Fe-Mn oxides fraction which may cause risk to aquatic life. The higher concentration of $\mathrm{Pb}$ values $29 \%, 26 \%, 27 \%$ and $26 \%$ was observed at the exchangeable fraction at sites B2, B3, B4 and B5, respectively (Fig. 2) and third stage (Fe-Mn oxide) of the extraction procedure (B3, and B4) was found higher concentration of $\mathrm{Pb}$ (42\% and 34\% ). A significant amount of the lead was found to be associated with exchangeable and bound to carbonate fractions and may pose risk to aquatic life. The association of lead with exchangeable fraction indicates dominance of anthropogenic sources through domestic wastes and municipal sewage and traffic-related $\mathrm{Pb}$ emissions. Remos et al. (1994) and Jha et al. (1990) also reported that lead is mostly present in $\mathrm{Fe}-\mathrm{Mn}$ oxide fraction in sediments of River Yamuna at Delhi. The chemical partitioning of sediment $\mathrm{Pb}$ was strongly dominated by $\mathrm{Fe}$ Mn oxide and residual fractions. It was found that anthropogenic $\mathrm{Pb}$ was strongly associated with exchangeable, Fe-Mn oxide and organic/ sulphide fractions in the sediments. The Fe-Mn oxide and the organic matter have a scavenging effect and may provide a sink for heavy metals. The release of the metals from the matrix is most likely to be affected by the redox potential and pH (Jain et al. 2007).

The total concentration of $\mathrm{Cu}$ varied from $54.20 \mathrm{mg} / \mathrm{kg}$ to $198.17 \mathrm{mg} / \mathrm{kg}$. The highest concentration was found at site B3. Copper showed a homogeneous distribution in all samples. A number of earlier studies on polluted sediments, extractable $\mathrm{Cu}$ is mainly associated with organic matter (oxidizable phase), where it is likely to occur as organically complexed metal species (Yu et al.2001, Marin et al. 1997). The $\mathrm{Cu}$ bound to the residual fraction in the 
sediments ranged from $27 \%$ to $53 \%$ of total. The next important phase in the sediment samples was the organic fraction $(21-51.0 \%)$. The major portion is bound to organic matter at most of the sites probably due to $\mathrm{Cu}$ has high affinity towards organic matter and chemically very active in complexing such metals (Pempkowiak et al. 1999; Jain, 2007). A large portion of $\mathrm{Cu}$ percentage of copper is also found in reducible fraction (Fe-Mn oxide).

The total concentration of $\mathrm{Zn}$ varied from $78.23 \mathrm{mg} / \mathrm{kg}$ to $362.90 \mathrm{mg} / \mathrm{kg}$ in the sediment of Bagmati River. Zinc was found mainly in the residual fraction, although its significant amount was in the fraction bound to hydrated iron and manganese oxides. Zn concentration varied from $21 \%$ to $39 \%$ in Fe-Mn oxide fraction and highest percentage (\%) was found at site B4 (Fig2). These findings are close to results found by other researchers. The predominant association of $\mathrm{Zn}$ with the $\mathrm{Fe}-$ Mn oxides (reducible fraction) of sediment has been widely recognized (Kuo et al.1983; Yu et al. 2001; Tsai et al. 2003), showing that the Zn adsorption onto these oxides has high stability constants.

\section{CONCLUSION}

The present study examined the distribution of heavy metals in the sediments of the Bagmati River, Nepal. By studying the distribution of the metals between the different phases, their bioavailability and toxicity can be determined.

The results obtained in this study showed that sediments of the Bagmati River in the urban areas is heavily polluted with untreated municipal wastewaters and industrial effluents and heavy traffic that act as an important factor contributing to the river pollution. The high proportions of potentially bio-available form (exchangeable) of toxic metals like Cd 36\%, $31 \%$ and $29 \%$ and $\mathrm{Pb} 29 \%, 26 \%$, and $27 \%$ in the urban area of the Bagmati River sediment. This potentially bio-available fraction could pose a serious risk to aquatic life and therefore can easily enter the food chain. The association of $\mathrm{Cd}$ and $\mathrm{Pb}$ with exchangeable fraction indicates dominance of anthropogenic sources through domestic wastes and municipal sewage and traffic-related $\mathrm{Pb}$ emissions. The higher concentration of $\mathrm{Pb}(42 \%$ and $34 \%)$ was found to be in the third stage (Fe-Mn oxide) of the extraction at the sites B3, and B4. The Fe-Mn oxide and the organic matter have a scavenging effect and may provide a sink for heavy metals. The release of the metals from the matrix is most likely to be affected by the redox potential and $\mathrm{pH}$. Sediments are ecologically important components of the aquatic habitat and are also a reservoir of pollutants. Speciation pattern of $\mathrm{Cu}$ and $\mathrm{Zn}$ in the Bagmati River shows only low to medium risk for the aquatic environment. Heavy metal pollution is of great concern because of their toxicity threatens to human health and the ecosystem. It is therefore recommended that, this river should be put under surveillance since it is one of the major sources of fresh water in this area.

\section{REFERENCES}

Chapman, P.M., Wang, F.Y., 1999. Appropriate applications of sediments quality values for metals and metalloids. Environ. Sci. and Techn. 33, 3937-3941.

Dojlido, J.R., Best G.A., 1993. Chemistry of Water and Water pollution. Ellis Horwood, England. 
Filho, P.J., Betemps, G.R., Mesenburg, A.P., Alfonso, P., 2013. Determination of trace metals in sediment samples of the Santa Barbara Channel / Pelotas / RS / Brazil

Forstner, U., 1985. Chemical forms and reactivities of metals in sediments. In Leschber, R., Davis, R. D. \& L'Hermie, P. (Eds.), Chemical methods for assessing bioavailable metals in sludges and soils, London, Elsevier.

Forstner, U., 1987. In Metal Speciation, Separation and Recovery. Lewis Publishers, Chelsea.

Forstner, U., Ahlf, W., Calmano, W., Kersten, M. and Schoer, J. 1990. Assessment of metal mobility in sludges and solid wastes, In: Metal Speciation in the Environment, NATO ASI Series, J. A. C. Broeckaert, S. Gucer and F. Adams, 1-41. Series G, Ecological Sciences, Springer, Berlin

Forstner, U., Wittman, G.T.W., 1983, Metal Pollution in Aquatic Environment, Springer-Verlag Berlin, Heidelberg, New York.

Hakanson, L., 1980. An ecological risk index for aquatic pollution control-A sedimentological approach. Water Research, 14, 975-1001.

Hoda ,H., Ahdy, H., Khaled, A.,2009. Heavy metals contamination in sediments of the western part of Egyptian Mediterranean Sea. Australian J. Basic and Appli. Sci. 3(4), 3330-3336.

Hongyi, N., Wenjing, D., Qunhe, W., Xingeng, C., Poential toxic risk of heavy metals from sediment of the Pearl River in South China. J. of Environ. Sci. 21, 1053-1058.
Hortellani, M.A., Sarkis, J.E.S., Abessa, D.M.S., Sousa, E.C.P.M., 2008. Avaliacao da contaminacao por elementos metalicos dos sedimentos do Estuario Santos-Sao Vicente (in Brazil). Quím. Nova. 31(1), 10-19.

Howard, J. L., Shu, J., 1996. Sequential extraction analysis of heavy metals using a chelating agent (NTA) to counteract resorption. Environ. Pollut. 91, 89-96.

Izquierdo, C., Usero, J.,Gracia, I. (1997) Speciation of heavy metals in sediments from salt marshes on the southern Atlantic coast of Spain, Mar. Pollut. Bull., 34: 123-128.

Jain, C. K., Malik, D. S., Yadav, R., 2007. Metal Fractionation Study on Bed Sediments of Lake Nainital, Uttaranchal, India. Environ. Monit. Assess. 130,129-139.

Jaradat, Q.M., Massadeh, A.M., Zaitoun, M.Z., Maitah, B.M., 2006. Fractionation and sequential extraction of heavy metals in the soil of scrap yard of discarded vehicles. Environ. Monit. Assess. 112, 197-210.

Jha, P.K., Subramanian, V., Stasawad, R., Griekan, V.R., 1990. Heavy metals in sediments of the Yamuna River (A tributary of the Ganges), India. Sci Total Environ. 95:7-27.

Juracek, K.E., Ziegler, A.C., 2009. Estimation of sediment sources using selected chemical tracers in the Perry lake basin, Kansas, USA. Intern. J. sediment Research 24, 108-125.

Kuo, S., Heilman, P.E, Baker, A.S., 1983. Distribution and forms of copper, zinc, cadmium, iron and manganese in soils 
near a copper smelter. Soil Sci. 135:101109.

Li, X. and Thornton, L.: 2001, Chemical partitioning of trace and major elements in soils contaminated by mining and smelting activities, Appl. Geochim. 16, 1693-1706.

Li, X., Poon, C. and Liu, P.: 2001, Heavy metal contamination of urban soils and street dusts in Hong Kong, Appl. Geochim. 16, 1361-1368.

Lopez-Gonzalez, N., Borrego, J., Morales, J. A., Carro, O., Lozano-Soria, O., 2006 Metal fractionation in oxic sediments of an estuary affected by acid mine drainage (south western Spain), Estuar. Coast. Shelf Sci., 68: 297-304.

Loska, K., Wiechula, D., 2003. Application of principle component analysis for the estmationof source heavy metal contamination in surface sediments from Rybnik Reservoir. Chemoshere, 51, 723733.

MacFarlane, G.R., Burchette, M.D., 2000. Cellular distribution of $\mathrm{Cu}, \mathrm{Pb}$ and $\mathrm{Zn}$ in the Grey Mangroove Avicennia marina (Forsk). Vierh Aqua. Bot., 68, 45- 59.

Marengo, E., Gennaro, M.C., Robotti, E., Rossanigo, P., Rinaudo, C., RozGastaldi, M., 2006. Investigation of anthropic effects connected with metal ions concentration, organic matter and grain size in Bormida river sediments. Anal.Chim. Acta. 560,172-183.

Marin, B., Valladon, M., Polve, M., Monaco, A.,1997. A reproducibility testing of a sequential extraction scheme for the determination of trace metal speciation in a marine reference sediment by inductively coupled plasma mass spectrometry. Analytic Chimica Acta, 342, 91-112.

Pekey, H., 2006. The distribution and sources of heavy metals in Izmit Bay surface sediments affected by a polluted stream. Marine Pollution Bulletin, 52: $1197-$ 1208.

Pempkowiak, J., Sikora, A., Biemacka, E., 1999. Speciation of heavy metals in marine sediments vs. their bioaccumulation by Mussels. Chemosphere, 39(2), 313-321.

Ramos, L., Hernandez, L.M., Gonzalez, M.J.,1994. Sequential fractionation of copper, lead, cadmium and zinc in soils from or near Donana National Park. J Environ Qual. 23, 50-57.

Rollinson, H.R., 1993. Using Geochemical Data: Evaluation, Presentation, interpretation. Longman, London.

Rubio, R., Lopez-Sanchez, J. F., Rauret, G., 1991. La especiacion solida de trazas de metales en sedimentos. Aplicaciỏn a sedimentos muy contaminados, Anal. De Quim., 87, 599-605.

Singh, M., Muller, G., and Singh, I.B., 2003, Geogenic distribution and baseline concentration of heavy metals in sediments of the Ganges river, India, J. Geochem. Explor. 80: 1-17.

Sutherland, R.A., Tack, F.M.G., 2007. Sequential extraction of lead from grain size fractionated river sediments using the optimized BCR Procedure. Water Air Soil Pollut. 84,269-284.

Tessier, P.G.C. Campbell, M. Bisson, 1979. Sequential Extraction for the Separation of Particulate Trace Metals. Anal. Chem. 51: 844-851. 
Tokalioglu,S., Kartal,S., Elçi, L., 2000. Determination of heavy metals and their speciation in lake sediments by flame atomic absorption spectrometry after a four-stage sequential extraction procedure. Anal. Chimica Acta, 413, 3340.

Trefry, L.H., Parsley, B.J., 1976. Heavy metal transport from the Mississippi river to the Gulf of Mexico. In: HL Windhom and RA Duce (Eds.). Marine Pollut. Trans. Lexington, 39-76.

Tsai, L.J., Yu. K.C, Chen, S. F., Kung, P.Y, Chang, C. Y., Lin, H., 2003. Partitioning variation of heavy metals in contaminated river sediment via bioleaching: effect of sulfur added to total solids. Water Research. 37, 4623-4630.
Viers, J., B. Dupre., J. Gaillardet., 2009, Chemical composition of sus pended sediments in World Rivers: New insights from a new database,Sci. Total Environ., 407, 853-868.

Yu, K.C., Tsai, L.J., Chen, S.F., Ho, S.T., 2001. Chemical binding of heavy metals in anoxic river sediments. Water Research. 35 (17), 4086-4094.

Zakir, H.M, Shikazono, N., Otomo, K., 2008. Geochemical distribution of trace metals and assessment of anthropogenic pollution in sediments of Old Nakagawa River, Tokyo, Japan. Am. J. Environ. Sci., 4(6): 661-672. 